\title{
Constrained genetic algorithms for optimizing multi-use reservoir operation
}

\author{
Li-Chiu Chang ${ }^{\text {a }}$, Fi-John Chang ${ }^{\text {b,* }}$, Kuo-Wei Wang ${ }^{b}$, Shin-Yi Dai ${ }^{b}$ \\ a Department of Water Resources and Environmental Engineering, Tamkang University, Taipei, Taiwan, ROC \\ ${ }^{\mathrm{b}}$ Department of Bioenvironmental Systems Engineering, National Taiwan University, Taipei, Taiwan, ROC
}

\section{A R T I C L E I N F O}

\section{Article history:}

Received 5 March 2010

Received in revised form 14 June 2010

Accepted 18 June 2010

This manuscript was handled by G. Syme, Editor-in-Chief, with the assistance of Soroosh Sorooshian, Associate Editor

\section{Keywords:}

Reservoir operation

Constrained genetic algorithms (CGA)

Penalty strategy

Ecological base flow

\begin{abstract}
A B S T R A C T
To derive an optimal strategy for reservoir operations to assist the decision-making process, we propose a methodology that incorporates the constrained genetic algorithm (CGA) where the ecological base flow requirements are considered as constraints to water release of reservoir operation when optimizing the 10-day reservoir storage. Furthermore, a number of penalty functions designed for different types of constraints are integrated into reservoir operational objectives to form the fitness function. To validate the applicability of this proposed methodology for reservoir operations, the Shih-Men Reservoir and its downstream water demands are used as a case study. By implementing the proposed CGA in optimizing the operational performance of the Shih-Men Reservoir for the last 20 years, we find this method provides much better performance in terms of a small generalized shortage index (GSI) for human water demands and greater ecological base flows for most of the years than historical operations do. We demonstrate the CGA approach can significantly improve the efficiency and effectiveness of water supply capability to both human and ecological base flow requirements and thus optimize reservoir operations for multiple water users. The CGA can be a powerful tool in searching for the optimal strategy for multiuse reservoir operations in water resources management.
\end{abstract}

(c) 2010 Elsevier B.V. All rights reserved.

\section{Introduction}

Reservoirs can increase the reliability of water supplies in promoting livelihoods, raising agricultural productivity, and reducing the farmers' vulnerability to droughts. Although the annual precipitation is abundant in Taiwan, the frequency and intensity of extreme hydrological events (such as floods and droughts) vary highly, which obviously restricts the effective use of water and causes insufficient water supply. To overcome the problem of insufficient water supply during periods of low flow, attention has been focused on improving water resources management, especially in optimization of reservoir operations (Chang and Chang, 2001; Chang et al., 2005; Chen et al., 2007). The majority of researches in water resources are devoted to developing ways to meet human water demands, while the explicit inclusion of environmental flow targets has received less attention. Lately, we, as water resources engineers, often face criticisms regarding water resources management due to the lack of careful assessments of environmental impacts caused by reservoir operations. In an attempt to minimize these negative impacts, the related environmental aspects must be taken into account in the management of water storage facilities (Bauer and Olsson, 2008; Galizia Tundisi

\footnotetext{
* Corresponding author. Tel.: +8862 23639461; fax: +886223635854.

E-mail address: changfj@ntu.edu.tw (F.-J. Chang).
}

and Matsumura-Tundisi, 2003; Gibbins et al., 2001; McCartney et al., 2005; Suen and Eheart, 2006).

In the last decades, the minimum environmental flow target gained the attention of scientists, engineers, and managers (Pusey, 1998; Stalnaker and Arnette, 1976; Tennant, 1976). The target was designed to maintain the minimum stream flows for sustaining aquatic ecosystem. It provided a single value that could be easily implemented as another objective to be optimized in water management programs. The implementation of a single flow, however, was found to eliminate the flow variability sustaining healthy and diverse aquatic communities. Lately, there has been a great deal of effort devoted to estimating environmental flow requirements and to the identification of the need for maintaining ecological flows to protect freshwater biodiversity (Richter et al., 1996; Poff et al., 1997; Lytle and Poff, 2004). We now understand the importance of mimicking components of the natural flow regime as targets for managing flow magnitude, frequency, and timing variables (Arthington et al., 2006; Chang et al., 2008, 2009). The flow regime, however, contains too many variables, which makes it very difficult to implement in water resources management. Moreover, translating general hydrologic-ecological principles and knowledge into specific management rules for particular river basins and reaches has remained a daunting challenge (Poff et al., 2003). Harman and Stewardson (2005) also mentioned that only a few published studies explicitly described the link between environmental flow targets and dam operating rules. To resolve the 
river management-driven issues and bridge the gap between a simple minimum stream flow target and the great complexity of the natural flow regime, we propose a realistic and feasible approach that incorporates the human demands with the most essential aspects of natural flow variability (i.e., the seasonal base flow requirements) as the key targets in searching for the optimal strategy of reservoir operation management.

In recent decades, evolutionary computation techniques, such as genetic algorithms, have become popular in global optimization application of reservoir planning and management in science and engineering (Cai et al., 2001; Huang et al., 2002; Suen and Eheart, 2006; Chen and Chang, 2007; Kerachian and Karamouz, 2007; Chang, 2008; Chaves and Chang, 2008; Chen and Chang, 2009). Most developed algorithms are capable of handling complex planning and management problems. Evolutionary computation techniques have received a great deal of attention regarding their potential in optimization techniques for complex systems. Nevertheless, they have not really produced a significant breakthrough in complex nonlinear problems because they do not address the issues of constraints in a systematic way. Only recently have several methods been proposed for handling nonlinear constraints by evolutionary algorithms for numerical optimization in water resources problems (Chang, 2008; Katsifarakis and Petala, 2006).

This study proposes a constrained genetic algorithm (CGA) for multi-use water resources management that incorporates human needs and ecological sustainability requirements. We take the reservoir's downstream ecological seasonal demands into consideration and intend to minimize the influence of hydraulic engineering structures on the river aquatic environment. First, the ecological base flow requirements are considered as constraints to water release of reservoir operation. Next, for each constraint, a reasonable penalty function is established in a constrained genetic algorithm adopted to search for the feasible solutions of reservoir operations in different yearly hydrological events in order to achieve the ecological base flow requirements of the Tahan River in wet and dry seasons. In summary, the CGA method is implemented to identify reference flows and assess the impacts on generalized shortage index (GSI) of human needs and ecological base flow requirements.

\section{Constrained genetic algorithms}

The genetic algorithm proposed by John Holland (Holland, 1975) has been broadly utilized to solve different optimization problems. The GA mimics some processes observed in natural evolution. It starts with a randomly generated initial population and progresses to improve the fitness of solutions through iterations by implementing operators including scheme selection (reproduction), crossover and mutation operators. Though the GAs are very efficient in searching for the optimal solutions of unconstrained problems, they still encounter some difficulties in solving constrained nonlinear optimization problems. Most optimization problems, however, are constrained problems. In other words, the search space is restricted to some limited subspace for optimization. For highly constrained problems, it is quite common to get mostly inferior solutions of small fitness values or infeasible solutions during the early stage of the search processes. It would usually cause early convergences or inefficient searches with ignorance of the infeasible and inferior solutions.

When the GAs are applied to nonlinear constrained problems, constraint handling becomes critical. During the past few years, several methods, such as rejection, repair, and penalization strategies, have been presented for handling constraints when using GAs to solve constrained optimization problems (Deep and Dipti, 2008). The advantage of the rejection and repair approaches is that only feasible solutions are generated. For highly constrained problems, these approaches, unfortunately, could make the search process extremely difficult because of the large number of infeasible solutions in population, which certainly restricts the evolution processes of the GAs and makes the search process inefficient in finding a solution without any constraint violation. The most popular approach to handling constraints in the GA community is to use penalty functions (Chang, 2008). A penalty function converts a constrained optimization model to an unconstrained one to suit the application of evolutionary techniques. The penalty cost is a function designed to penalize infeasible solutions by reducing their fitness values in proportion to the number and the magnitude of constraint violations and is also a penalty multiplier to effectively guide the search direction towards promising solutions in the genetic search (see Fig. 1).

The penalty functions for problems with inequality constraints are divided into two categories: the exterior and the interior functions. For the interior penalty functions, the constraints act as barriers to forcing the generated search points to be always within the feasible domain (Abedian et al., 2006). This is the reason why the interior penalty functions could not be incorporated into GA optimization methods. Nevertheless, for the exterior penalty functions, a penalty value is added to the violated solutions by taking the number of violated constraints and their distance to the feasible domain into account. Lately, researchers have proposed some effective penalty functions to improve the efficiency of the GAs (Deep and Dipti, 2008; Katsifarakis and Petala, 2006; Michalewicz and Schoenauer, 1996; Richardson et al., 1989). However, there is

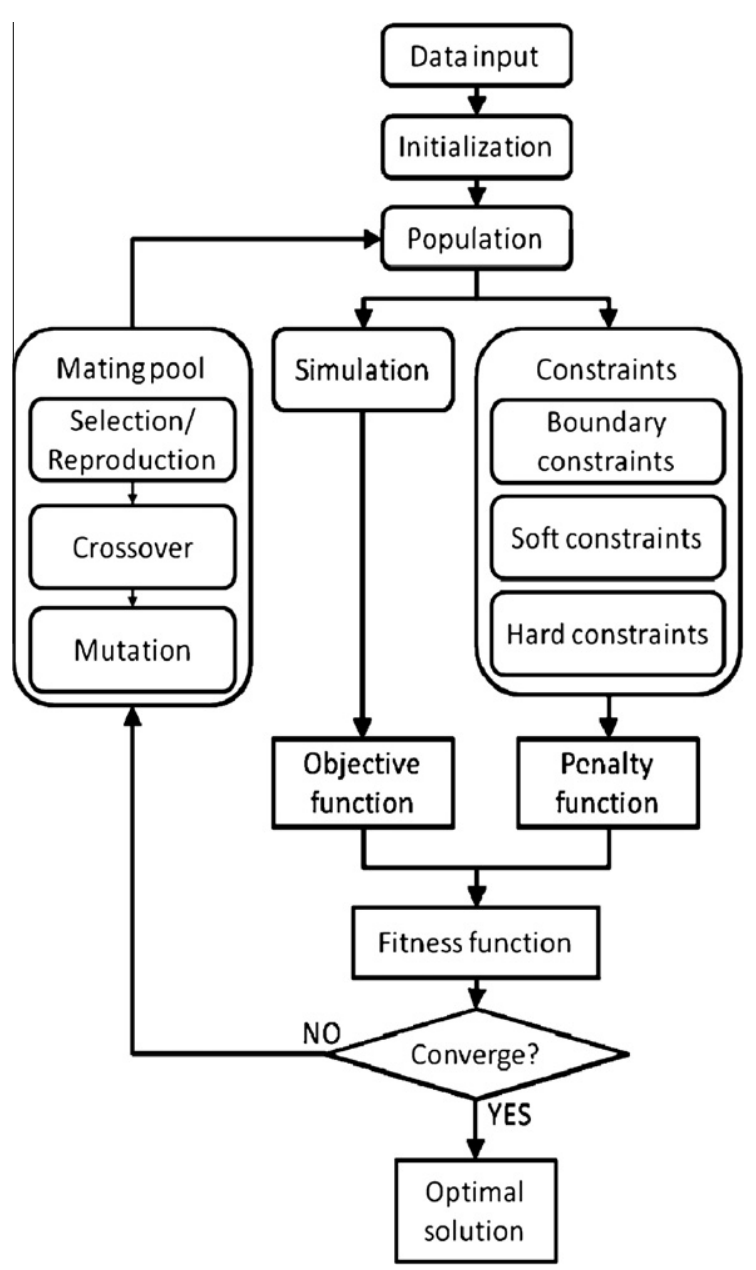

Fig. 1. The architecture of the CGA search process. 
no general guideline for designing effective penalty functions and these methods are quite problem dependent.

In general, an optimization problem can be written in nonlinear programming form:

$\min f(\vec{x})$

subject to $g_{i}(\vec{x}) \leqslant 0 \quad i=1,2, \ldots, l$

$$
\begin{aligned}
& h_{j}(\vec{x})=0 \quad j=1,2, \ldots, m \\
& x_{k}^{l} \leqslant x_{k} \leqslant x_{k}^{u}(\vec{x})=0 \quad k=1,2, \ldots, n
\end{aligned}
$$

where $f(\vec{x})$ is the objective function with n decision variables $(\vec{x})$, $g_{i}(\vec{x})$ is the $i$ th inequality constraint, and $h_{j}(\vec{x})$ is the $j$ th equality constraint. $x_{k}^{l}$ and $x_{k}^{u}$ are lower and upper bounds on the $k$ th variable $x_{k}$.

To easily implement the GA in solving an optimization problem, we usually adopt the external penalty functions to convert a constrained optimization problem into an unconstrained one. There are two possible ways to construct the fitness function with penalty terms. The easiest way to construct a fitness function is to add penalty values associated with those infeasible solutions to the objective function.

$$
F(\vec{x})= \begin{cases}f(\vec{x}) & x \in \text { feasible region } \\ f(\vec{x})+p(\vec{x}) & x \notin \text { feasible region }\end{cases}
$$

where $p(\vec{x})$ is the penalty function. However, there is no straightforward way to find a suitable and effective penalty function, and a troublesome trial and error procedure must be conducted in general to obtain a suitable set of penalty functions. In this study, we devoted a large amount of effort to combining different types of penalty functions. Our experiences showed that the multiplication form, overall, performs more effectively in obtaining reasonable solutions. Consequently, the corresponding penalty function of Eq. (6) is used to construct the fitness function.

$p(\vec{x})=\prod_{i=1}^{l}\left(1+c_{i} \max \left(g_{i}(\vec{x}), 0\right)\right) \times \prod_{j=1}^{m}\left(1+d_{j}\left|h_{j}(\vec{x})\right|\right)$

where $c_{i}$ and $d_{i}$ are the penalty weights of the inequality and equality constraints, respectively.

\section{Case study}

\subsection{Study area}

The Tahan River is $135 \mathrm{~km}$ long with an average channel slope of $1 / 37$, and its watershed covers an area of $1163 \mathrm{~km}^{2}$. The watershed has received an annual average of $2410 \mathrm{~mm}$ of rainfall in the last 40 years; however, the rainfalls were uneven-over $70 \%$ occurred between May and October (typhoon seasons). The ShihMen Reservoir, located upstream of the Tahan River, satisfies the multiple purposes of water supply including irrigation, hydropower generation, industrial and domestic water uses, flood control, and recreation. The watershed of the Shih-Men Reservoir covers an area of $763.4 \mathrm{~km}^{2}$ with an effective storage capacity of $2.35 \times 10^{8} \mathrm{~m}^{3}$. The water supply for human demands, such as hydropower generation, agriculture and industry uses together with drinking water, is under pressure nowadays. This study mainly concentrates on how to arrange water release from the reservoir to best satisfy human demands and ecological base flow requirements in the downstream area of the Shih-Men Reservoir. Fig. 2 shows the study area of watershed, with the thick line indicating the downstream area and the operation system of the ShihMen Reservoir and the Tahan River. Fig. 3 presents the time series of annual flows and wet and drought seasonal flows during the period of 1984-2003. We can find great variability in those series, and the flow in the wet season is much greater than the flow in the drought season.

\subsection{Ecological base flow requirements}

Generally, the minimum flow designates a minimum range of water flow that prevents the regional ecosystem from significant harm, and above which water is available for reasonable beneficial use. The minimum base flow requirements should consider the ability of aquatic communities to remain healthy. Recently, a minimum base flow requirement was proposed for the water resources management by the Water Resources Agency in Taiwan. We, however, like to note that an obtained optimal minimum base flow may not be appropriate for establishing the flow regime of the entire river. Furthermore, the optimal minimum base flow could only provide a viable research starting point for discussion, yet not necessarily be adopted as the minimum flow required for the river.

The determination of minimum base flow may be based on a wide variety of existing information, including biological and topographical information, scientific literature, water flow data, and output from computer simulation models. There are methods for generating the minimum base flow, such as: (1) using historical flow records to identify the natural flow over time; (2) investigating the hydraulic geometry of the river; (3) using local and traditional knowledge to establish flow; and (4) matching flow levels in order to maintain aquatic species. Since most of these methods were developed according to site-specific requirements, there are no universal methods that can be used to transfer (Bauer and Olsson, 2008). Table 1 provides minimum base flow requirements based on the habitat methods $(0.6-4 \mathrm{cms})$ and the historical flow method $\left(\mathrm{Q}_{95}\right)$ (Chang, 2004) in the Tahan River where data were acquired from previous studies. In this study, we also compute the minimum 10-day average flows in dry and wet seasons on the basis of historical data of the last 40 years (1964-2003). It appears that the minimum 10-day average flows for dry and wet seasons are $6.75 \mathrm{cms}$ and $12.28 \mathrm{cms}$, respectively. We regard these values as the minimum ecological base flow requirements that will be deemed as constraints to objectives in searching for the optimal reservoir operation strategy of water resources management.

\section{The reservoir operation formulation}

\subsection{Objective function}

We consider the human demand and ecological base flow requirements of the downstream area in order to avoid long-term water deficiency and overly focus on short-term water deficiency. These two goals, however, should not be considered as two independent objectives since they are not always in conflict. In this study, we consider the ecological base flow requirements as constraints when optimizing the reservoir operations. So, the objective function is the human demand shown in the Eq. (7). Our goal is to optimize the objectives while complying with relevant regulations and physical constraints. The objective function should primarily meet different user requirements and prevent from serious water shortages that would affect the downstream environment and ecosystem and eventually severely harm flora and fauna. Consequently, the amount of deficiency in each time step is squared for rapidly increasing the function value, which can apparently display the volume of water shortage within a specific 10-day period. Meanwhile, a continuous water shortage might be inconvenient for all users and also result in a cumulative effect on the ecosystem. Therefore, the objective function is defined cumulatively as the square of the deficit in each period multiplied by the number of continuous periods without water release, shown in Eq. (7). 


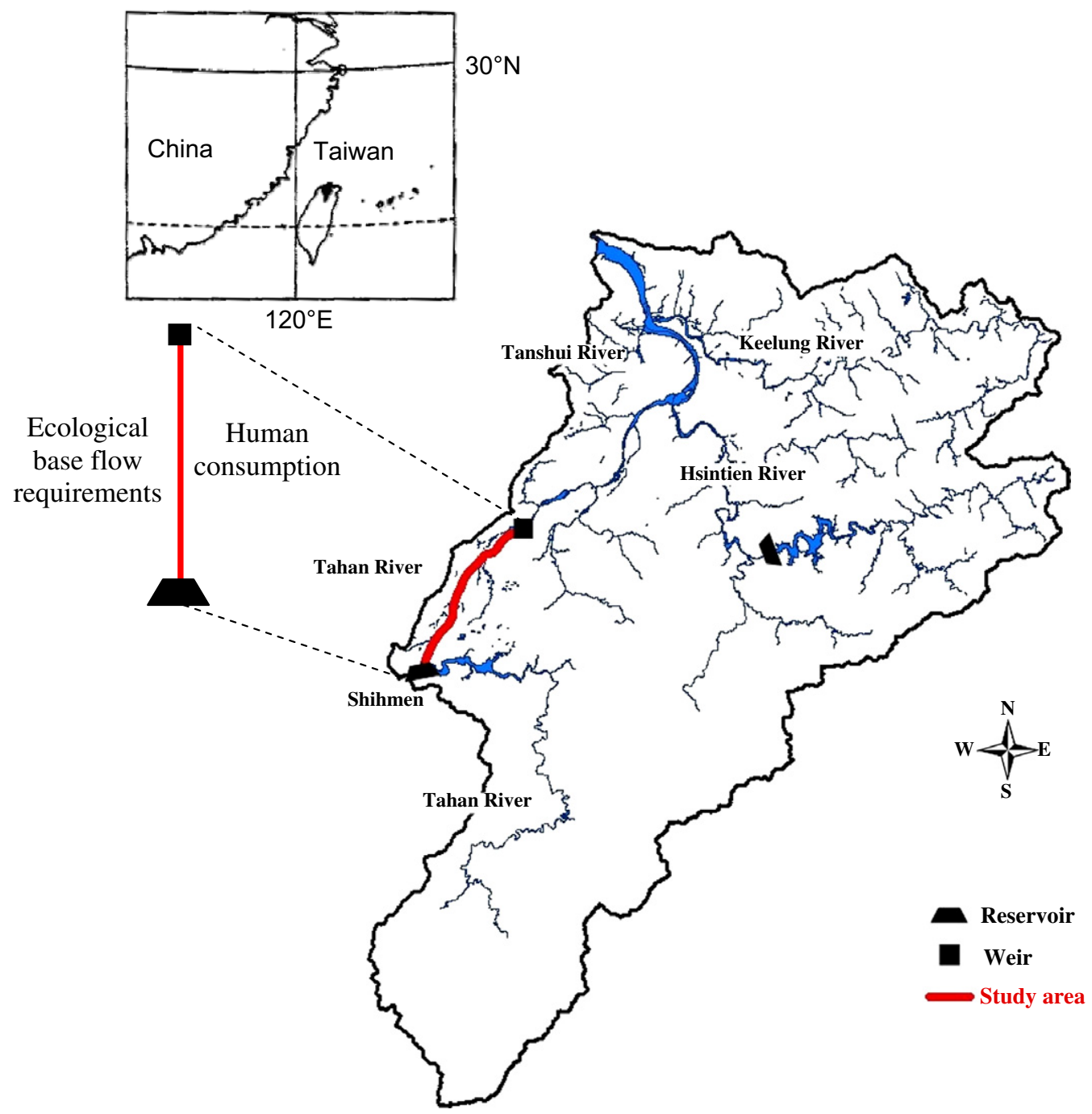

Fig. 2. The locations of the Shih-Men Reservoir and the Tahan River.

$\min f(\vec{S})=\min \left\{\sum_{i=1}^{36}\left[\left(\max \left(0, \frac{D_{i}-R d_{i}}{D_{i}}\right)\right)^{2} \times n_{i}\right]\right\}$

where $D_{i}$ and $R d_{i}$ are the human water demand and downstream water release in the $i$ th 10-day period. The purpose of the variable, $n_{i}$, is to enlarge the effect of continuous deficiency and to avoid an occurrence of a continuous deficiency.

\subsection{Constraints}

The reservoir operations should follow the operating regulations and comply with physical constraints, such as reservoir water balance and the permissible bounds of water release and storage, as well as the final target of water storage. The operation of the Shih-Men Reservoir is guided by M-5 rule curves. A detail of the M-5 rule curves and its operating rules can be found in Chang et al. (2005). The constraints shown in Eqs. (8)-(14) are related to the water balance equations, the upper and lower bounds on release and storage, the ecological base flow requirements, and general standards of operating procedures, respectively.

$S_{i}=S_{i-1}+I_{i}-\left(R d_{i}+R c_{i}\right)$

$0 \leqslant S_{i} \leqslant S_{\max }$
$S_{i} \prec S_{i}^{U}, i=1 \sim 15$ (wet season)

$S_{i} \succ S_{i}^{L}, i=16 \sim 36$ (dry season)

$S_{36} \succ 0.9 S_{0}$

$R d_{i} \succ \max \left[E_{i} D_{i}\right]$

$S_{i}, I_{i}, D_{i}, E_{i}, R d_{i}, R c_{i} \geqslant 0$

where $S_{i}, I_{i}, D_{i}, E_{i}, R d_{i}$ and $R c_{i}$ are the storage, inflow, downstream human water demand, ecological base flow requirements, downstream water release (including the release to ecological base flow), and water release of other canals in the ith 10-day period, respectively; $S_{i}^{U}$ and $S_{i}^{L}$ are the upper and lower storage limits of M-5 rule curve; $S_{\max }$ is the maximum storage; $\succ$ and $\prec$ similar to $>$ and $<$ can be violated slightly. Eq. (8) is the mass balance equation. Eq. (9) is the storage capacity. Eqs. (10) and (11) are the storage limits with respect to dry and wet seasons where the storage should be maintained close to the upper limit in a wet season and the reservoir should hold its storage higher than the lower limit curve to prevent from a serious drought in a dry season. Eq. (12) confines the condition at the final stage of reservoir storage. Eq. (13) means the downstream water release must exceed human water demand 


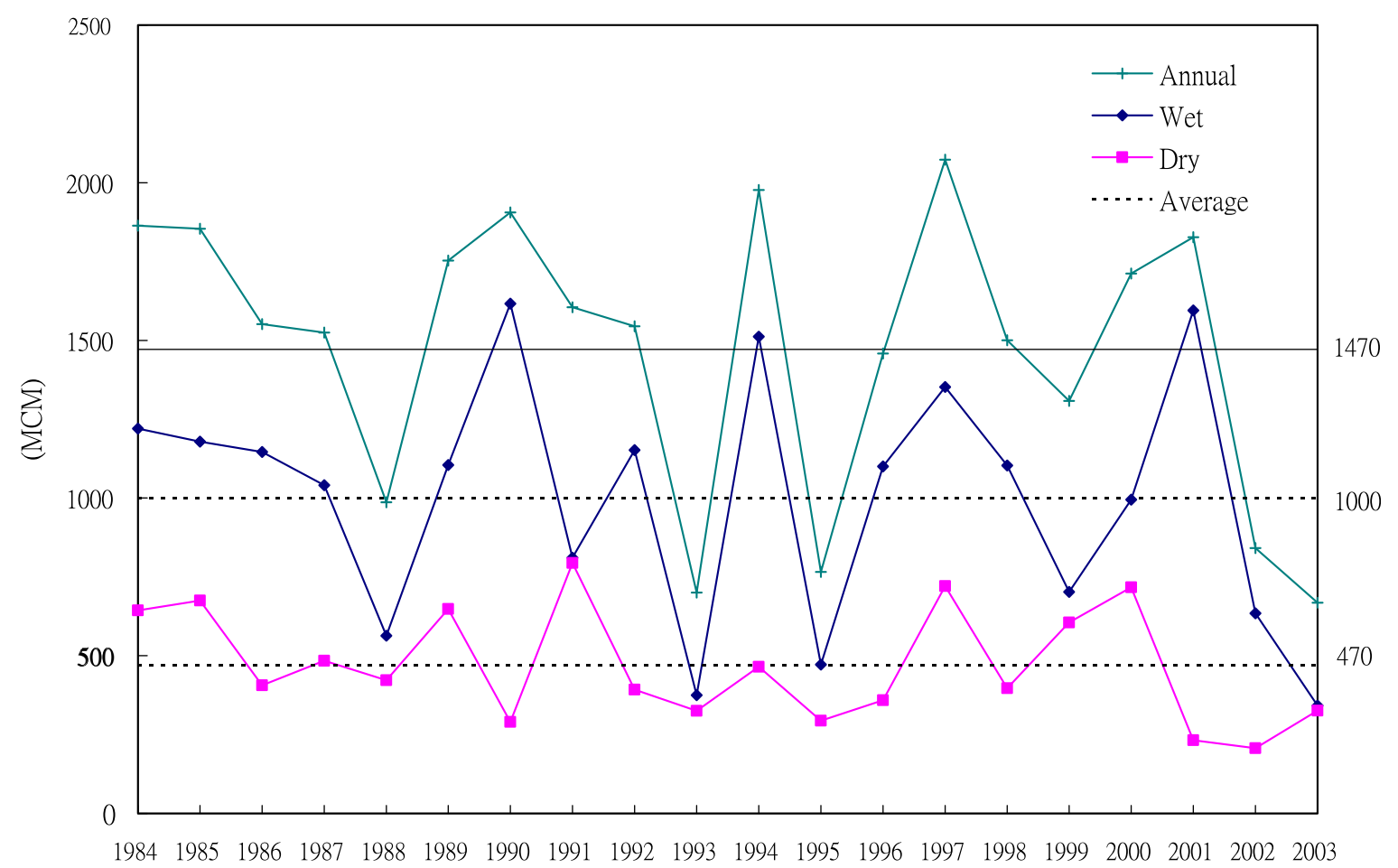

Fig. 3. The time series of annual flows and wet and drought seasonal flows during the period of 1984-2003.

Table 1

The estimated minimum ecological base flow requirements for the Tahan River.

\begin{tabular}{|c|c|c|c|}
\hline No. & $\begin{array}{l}\text { Ecological base flow } \\
\text { requirements }\end{array}$ & Methods & References \\
\hline 1 & $0.6-4 \mathrm{cms}$ & Habitat methods, considering the needs of two kinds of fishes (1986-2000) & Water Resources Agency (Chang, 2004) \\
\hline 2 & $8.96 \mathrm{cms}$ & $\begin{array}{l}\text { Historical flow method: using input and flow of side calculation Q95 (1965- } \\
\text { 2002) }\end{array}$ & $\begin{array}{l}\text { Northern Region Water Resources Office (Chang, } \\
\text { 2004) }\end{array}$ \\
\hline 3 & $\begin{array}{l}\text { Dry: } 6.75 \mathrm{cms} \\
\text { Wet: } 12.28 \mathrm{cms}\end{array}$ & $\begin{array}{l}\text { Mean annual minimum 10-day flow during the dry and wet periods within } \\
\text { 1964-2004 }\end{array}$ & This study \\
\hline
\end{tabular}

and ecological base flow requirements. Eq. (14) shows the negative condition.

\subsection{Fitness function and penalty function}

To implement the constrained GA, the constraints must be integrated into the objective function $f(\vec{S})$ to form the fitness function $F(\vec{S})$ through some appropriate penalty function $p(\vec{S})$. The fitness function is defined in Eq. (16).

$F(\vec{S})=f(\vec{S}) p(\vec{S})$

$p(\vec{S})=1+\sum_{j=1}^{n_{c}} \sum_{i=1}^{n_{x}} g_{j i}(\vec{S}), \quad i=1,2, \ldots, n_{x} ; \quad j=1,2, \ldots, n_{c}$

$g_{j i}(\vec{x})= \begin{cases}0 & x \in \text { feasible region } \\ g_{j i}(\vec{x}) & x \notin \text { feasible region }\end{cases}$

where $n_{x}$ is the number of genes, i.e., 36 genes (variables); $n_{c}$ is the number of constraints; $g_{j i}$ is a penalty function of the $j$ th constraint of the $i$ th variable.

The constraints are divided into three categories: boundary constraints, soft constraints and hard constraints. Boundary constraints, Eqs. (9) and (14), confine the search space to the designed ranges. Soft constraints, Eqs. (10)-(13), are allowed to be violated and punished by the penalty terms, which will slightly decrease the fitness values when reaching a low (tiny) degree of violation, but significantly decrease the fitness value when reaching a high degree of violation. That means these constraints are not strictly complied with to certain degrees. The violation degrees of soft constraints will guide the GA towards a feasible solution space in the search process. The corresponding constants of penalty terms cannot be set to large values; otherwise, it will be difficult to find the optimal fitness values.

In the computation process, if various genes have reached the limits of conditions, then we have to apply the respective penalties according to the degrees of limit violations. This fitness would rapidly decrease. This penalty mechanism can be more effective through reducing the probability of choosing a worse solution and suitably respond to the decision-making process of choosing an infeasible solution.

We consider the differences between constraints and their degrees of violations. The penalty function of each limit is set through a number of trial and error processes and presented as follows:

(1) When the value of water release is smaller than zero, which is apparently an infeasible solution, the penalty mechanism for violating the physical condition is to multiply the 
obtained negative release value by an appropriate penalty value (see Eq. (18)). This set value is crucial to the search for different hydrological events. In wet or normal hydrological years, the penalty value should be set to a large value to obtain a convergent solution earlier. However, in drought years, the search algorithm cannot obtain a convergent solution because all genes do not satisfy the boundary constraints; therefore, a smaller value should be considered for the penalty value.

$g_{1 i}(\vec{S})=-1000 R_{i} \quad$ if $\quad R_{i}<0, \quad i=1 \sim 36$

(2) During wet seasons, we want to hold the water at a certain level to avoid a water shortage in the next drought period. As a consequence, when the water storage is below the corresponding upper storage limit of M-5 rule curve, the penalty function is set to two-times the difference of water storage and the corresponding upper storage limit of M-5 rule curve $\left(S_{i}<S_{i}^{U}\right)$ as shown in Eq. (19).

$$
g_{2 i}(\vec{x})=\left(S_{i}^{U}-S_{i}\right) \times 2 \quad i=1 \sim 15
$$

(3) During dry seasons, if water storage is lower than the corresponding lower storage limit of the M-5 rule curve $\left(S_{i}<S_{i}^{L}\right)$, the penalty function is set as follows:

$g_{3 i}(\vec{S})=\left(S_{i}^{L}-S_{i}\right) \times 2, \quad i=16 \sim 36$

(4) To prevent a shortage of water supply, the water storage should be maintained at a certain level all the time. When the water storage is below the critical lower limit of M-5 rule curve, the penalty function is set at four-times the difference of water storage and the critical lower limit of the M-5 rule curve as follows:

$g_{4 i}(\vec{S})=\left(S_{i}^{C L}-S_{i}\right) \times 4, \quad i=1 \sim 36$

where $S_{i}^{C L}$ is the critical lower limit storage of M-5 rule curve in the ith 10-day period.

(5) To maintain the initial water storage of each year at a similar condition, we should set the initial condition similar to the condition at the end of the previous year. The penalty function will be applied if the storage at the end of the year is $10 \%$ less than that of at the beginning of the year. If the water storage at the end of the year is below $50 \%$ of the lower limit of the M-5 rule curve, a penalty function is implemented as follows:

$$
\begin{aligned}
& g_{5 i}(\vec{S})=\left(S_{0}-S_{i}\right) \times 5, \quad i=36 \\
& g_{5 i}(\vec{S})=\left(0.5 S_{36}^{L}-S_{i}\right) \times 5, \quad i=6
\end{aligned}
$$

(6) For maintaining the ecological base flow requirements, we also set a penalty function if the volume of water release is less than that of the ecological base flow demand. The penalty function is set as follows:

$$
g_{6 i}(\vec{S})=\left(E_{i}-R d_{i}\right) \times 10, \quad i=1 \sim 36
$$

The coefficients defined in the above functions are based mainly on a subjective manner through a great number of trial and error processes for effectively obtaining suitable solutions.

\subsection{Setting parameters of the genetic algorithm}

The constrained GA is applied to searching for the optimal level of water storage within 1 year according to the designed objective and constraints. The inflow records of the last 20 years (19842003) are used. A 10-day period, which is a traditional reference time frame in Chinese agricultural society, is used as a time step. According to this scale, each month has three time steps, and hence every year has 36 time steps. Consequently, in each year, there are 36 water storages (variables) that need to be identified and the corresponding water release histogram can then be obtained. The initial value of water storage in each year is set the same as the value of water storage at the end of the previous year, and a year-overyear search is continuously operated and recorded for 20 years (1984-2003). The related GA's parameters used in this study are listed in Table 2.

\section{Results}

\subsection{Evaluation indicator}

The CGA search results are compared with the historical operations, i.e. the simulation results based mainly on the M-5 operating rule curves which only considered human demand. The generalized shortage index (GSI) proposed by Hsu (1995) is used to present the status of frequency and intensity of water shortage. Its formula is given as follows.

$\mathrm{DPD}=\sum(\mathrm{DDR}(\%) \times \mathrm{NDC})$

$\mathrm{GSI}=\frac{100}{N} \sum_{i=1}^{N}\left(\frac{\mathrm{DPD}_{i}}{100 \times \mathrm{DY}_{i}}\right)^{k}$

where DDR is 10-day deficit rate, i.e., total deficit in a period/water demand in the period $\times 100 \%$; NDC is the number of 10 -days in a continuous deficit; $\mathrm{DY}_{i}$ is the number of 10-day periods in a year (=36); $N$ is the number of sample years; $k$ is a constant, usually set as 2 .

\subsection{Evaluating different hydrological events}

To investigate the suitability and reliability of the proposed CGA, we consider three cases of ecological base flow requirements: Case I - $4 \mathrm{cms}$, Case II $-8.94 \mathrm{cms}$, and Case III $-6.85 \mathrm{cms}$ for dry seasons and $12.28 \mathrm{cms}$ for wet seasons, respectively. The annual historical operations and CGA search results of 1984-2003 are presented in Tables 3 and 4 and Fig. 4, respectively, and the 20-year mean values of those results are summarized in Table 5 .

Table 3 represents the water shortages of human demand associated with historical operations and CGA results based on different ecological base flow requirements. We found that most of the water shortages of human demand in the drought years were much larger than those in wet years. Table 4 represents the water shortages of ecological requirements associated with historical operations and CGA results based on different ecological base flow requirements. We also found (1) the water shortages of ecological requirements would only occur in four drought years as the ecological base flow requirement was set to $4 \mathrm{cms}$; (2) the water shortages of ecological requirements would increase dramatically as the ecological base flow requirement increased to $8.94 \mathrm{cms}$; (3) for the ecological base flow requirements of dry and wet seasons $(6.75 \mathrm{cms}$ for dry seasons $/ 12.28 \mathrm{cms}$ for wet seasons), the water shortages of ecological requirements in most of the simulation years would be slightly smaller than those of the ecological base flow requirements set to $8.94 \mathrm{cms}$. This phenomenon is eminent in the years of 1986, 1990, 1992, 1996, 2001 and 2002. Those 
Table 2

Parameters of the CGA.

\begin{tabular}{|c|c|}
\hline $\begin{array}{l}\text { GA } \\
\text { parameters }\end{array}$ & Setting value \\
\hline $\begin{array}{l}\text { Coding } \\
\text { method }\end{array}$ & Real coded \\
\hline $\begin{array}{l}\text { Population } \\
\text { size }\end{array}$ & 1000 \\
\hline Generation & $>500$ \\
\hline Selection & Roulette wheel selection with elite strategy \\
\hline Crossover & Linear interpolation method \\
\hline $\begin{array}{l}\text { Crossover } \\
\text { rate }\end{array}$ & 0.8 \\
\hline Mutation rate & 0.1 \\
\hline $\begin{array}{l}\text { Constraint } \\
\text { method }\end{array}$ & Penalty function \\
\hline Stop criteria & $\begin{array}{l}\text { 1. The improving rate of fitness is smaller than } 0.02 \text {. } \\
\text { 2. The difference of fitness between consecutive genera- } \\
\text { tions is smaller than } 100 \text {. }\end{array}$ \\
\hline
\end{tabular}

Table 3

The water shortages of human demand associated with historical operations and CGA results based on different ecological base flow requirements.

\begin{tabular}{|c|c|c|c|c|c|}
\hline \multirow[t]{2}{*}{ Type } & \multirow[t]{2}{*}{ Year } & \multicolumn{3}{|c|}{ CGA results } & \multirow[t]{2}{*}{ Historical operations } \\
\hline & & I & II & III (dry \& wet) & \\
\hline \multirow[t]{8}{*}{ Drought } & 1988 & 1.5 & 0.8 & 0.1 & 50 \\
\hline & 1993 & 60 & 63 & 65 & 74 \\
\hline & 1995 & 63 & 59 & 58 & 89 \\
\hline & 1996 & 3 & 1 & 0.2 & 54 \\
\hline & 1998 & 4 & 11 & 0.7 & 44 \\
\hline & 1999 & 0 & 0 & 0 & 47 \\
\hline & 2002 & 52 & 66 & 62 & 40 \\
\hline & 2003 & 64 & 67 & 69 & 82 \\
\hline \multirow[t]{4}{*}{ Normal } & 1986 & 7 & 11 & 8 & 68 \\
\hline & 1987 & 0 & 0 & 0 & 68 \\
\hline & 1991 & 0 & 0 & 0 & 30 \\
\hline & 1992 & 4 & 0.6 & 0.5 & 28 \\
\hline \multirow[t]{8}{*}{ Wet } & 1984 & 0 & 0 & 0 & 18 \\
\hline & 1985 & 0 & 0 & 0 & 45 \\
\hline & 1989 & 0 & 0 & 0 & 35 \\
\hline & 1990 & 34 & 36 & 29 & 30 \\
\hline & 1994 & 0 & 0.1 & 0 & 13 \\
\hline & 1997 & 0 & 0 & 0 & 56 \\
\hline & 2000 & 0 & 0 & 0 & 31 \\
\hline & 2001 & 36 & 49 & 36 & 41 \\
\hline
\end{tabular}

Remark: three different ecological base flow requirements: I - $4 \mathrm{cms}$; II - $8.94 \mathrm{cms}$; III $-6.75 \mathrm{cms}$ in dry seasons and $12.28 \mathrm{cms}$ in wet seasons.

years were marked in Table 4, and their dry season inflows are less than average, while their wet season inflows are larger than the average; (4) all water shortages of ecological requirements obtained from the CGA method are dramatically decreased as compared with those obtained from historical operations. The annual results of GSI obtained by the CGA and historical operations are shown in Fig. 4. It demonstrates that (1) the GSI values obtained from the constrained GA for all cases are much smaller than those of historical operations; (2) most of the GSI values obtained from CGA are very small (close to zero) and only four larger GSI values (greater than 5.0) happen in very dry years (i.e. 1993, 1995, 2002, and 2003); and (3) the corresponding GSI values slightly increased in only a few years even though the ecological base flow requirements greatly increased from Cases I $(4 \mathrm{cms})$, to II $(8.94 \mathrm{cms})$, up to III $(6.75 \mathrm{cms}$ for dry seasons $/ 12.28 \mathrm{cms}$ for wet seasons) by using CGA method. In summary, these results based on historical operations indicate that (1) the operations could not meet the water demands of human demand and would result in large GSI and water shortages in an almost 20-year simulation period; and (2) the water release to the downstream of the Tahan River would approximately provide $4-8.94 \mathrm{cms}$ for maintaining ecological base flow requirements in different seasons. As we closely examine the CGA search results, quite similar results are obtained for these three different ecological base flow requirements. These results indicate that by means of the CGA search, the water release from a reservoir could provide approximately $9 \mathrm{cms}$ for downstream ecological base flow and would not cause any significant water shortage in most of the years.

Table 5 gives the mean values of different indices within their periods for the CGA and historical operations. It is obvious that the mean values of GSI of historical operations for the last 20 years are larger than 20 and those of GSI generated by the CGA method for Cases I-III are all smaller than 2. Moreover, the mean values of water shortages of three different ecological base flow requirements in historical operations are 2,33 , and $30 \mathrm{MCM}$, respectively, while those of shortages generated by the CGA method are 1, 29, and $23 \mathrm{MCM}$, respectively. It appears the CGA search results in terms of both GSI and water shortages of human demand and ecological base flow requirements are all much smaller than the results obtained from historical operations in the past 20 years.

\section{Conclusion}

Evolutionary computation techniques have great potential in optimizing complex systems. This study proposes a constrained genetic algorithm (CGA) for multi-use reservoir management that incorporates human demand requirements and ecological base flow requirements. The ecological base flow requirements are converted as constraints to the CGA. To implement the CGA, the constraints are integrated into the objective function configured with appropriate penalty functions to form the fitness function. Constraints are allowed to be violated and can be punished by the penalty terms. The violation degrees of soft constraints would guide the GA towards a feasible solution space in the search process. To incorporate these penalty functions into the objective function to form the fitness function, our experience indicates the multiplication form of the penalty function, in general, is more effective in obtaining reasonable solutions. The CGA search could be very efficient by using the penalty mechanism which is capable of reducing the probabilities of choosing worse solutions and can suitably guide the search direction towards promising solutions during genetic search.

The CGA techniques and advanced system analysis methods have been implemented to search for the feasible solutions of the Shih-Men Reservoir operation in twenty different yearly hydrological events, and to assess the impacts of water shortages on ecological base flow requirements and human demand. According to previous studies and historical flows of the Tahan River, different ecological base flow requirements have been set for the downstream area: Case I - $4 \mathrm{cms}$; Case II - $8.94 \mathrm{cms}$; and Case III $6.75 \mathrm{cms}$ for dry seasons and $12.28 \mathrm{cms}$ for wet seasons. Based on historical records of reservoir water release, the water release could usually provide more than $4 \mathrm{cms}$ flow for human demand and downstream ecological base flow requirements. But as the goal of water release is set to $8.94 \mathrm{cms}$ (Case II), the reservoir would face serious water shortages, i.e., large values of water shortage, in drought years if the traditional M-5 rule curves are used. On the other hand, the values of GSI would dramatically decrease as the proposed constrained GA is used in search of optimal reservoir operations. Moreover, the reservoirs could provide more water for ecological base flows if CGA method is used. We demonstrate that the constrained GA can effectively incorporate the constraints 
Table 4

The water shortages of ecological flow requirements associated with historical operations and CGA results based on different ecological base flow requirements.

\begin{tabular}{|c|c|c|c|c|c|c|c|c|c|c|}
\hline \multirow[t]{2}{*}{ Type } & \multirow[t]{2}{*}{ Year } & \multicolumn{3}{|c|}{ Hydrological characteristics } & \multicolumn{3}{|c|}{ CGA results } & \multicolumn{3}{|c|}{ Historical operations } \\
\hline & & Dry & Wet & Annual & I & II & III & I & II & III \\
\hline \multirow[t]{8}{*}{ Drought } & 1988 & - & - & - & 0 & 23 & 27 & 0 & 34 & 33 \\
\hline & 1993 & - & - & - & 4.6 & 93 & 97 & 5.6 & 78 & 60 \\
\hline & 1995 & - & - & - & 13 & 85 & 83 & 8.7 & 96 & 80 \\
\hline & $1996^{*}$ & - & + & 0 & 0 & 20 & 1 & 0 & 30 & 29 \\
\hline & 1998 & - & + & 0 & 0 & 22 & 24 & 0 & 34 & 37 \\
\hline & 1999 & + & - & - & 0 & 0 & 0 & 0 & 16 & 15 \\
\hline & $2002^{*}$ & - & - & - & 4 & 88 & 65 & 5.6 & 55 & 62 \\
\hline & 2003 & - & - & - & 4 & 98 & 102 & 14.3 & 115 & 127 \\
\hline \multirow[t]{4}{*}{ Normal } & $1986^{*}$ & - & + & + & 0 & 25 & 0 & 0 & 23 & 18 \\
\hline & 1987 & 0 & + & + & 0 & 0 & 0 & 0 & 15 & 10 \\
\hline & 1991 & + & - & + & 0 & 0 & 0 & 0 & 7 & 11 \\
\hline & $1992^{*}$ & - & + & + & 0 & 13 & 5 & 0 & 19 & 16 \\
\hline \multirow[t]{8}{*}{ Wet } & 1984 & + & + & + & 0 & 0 & 0 & 0 & 15 & 16 \\
\hline & 1985 & + & + & + & 0 & 0 & 0 & 0 & 30 & 20 \\
\hline & 1989 & + & + & + & 0 & 0 & 0 & 0 & 10 & 5 \\
\hline & $1990^{*}$ & - & + & + & 2 & 52 & 18 & 0 & 22 & 8 \\
\hline & 1994 & 0 & + & + & 0 & 0.5 & 0 & 0 & 14 & 11 \\
\hline & 1997 & + & + & + & 0 & 0 & 0 & 0 & 24 & 18 \\
\hline & 2000 & + & 0 & + & 0 & 0 & 0 & 0 & 10 & 16 \\
\hline & $2001^{*}$ & - & + & + & 0.6 & 64 & 33 & 0.7 & 21 & 11 \\
\hline
\end{tabular}

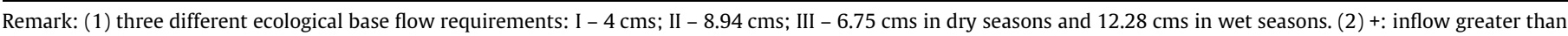
average; -: inflow less than average; o: inflow equal to average.

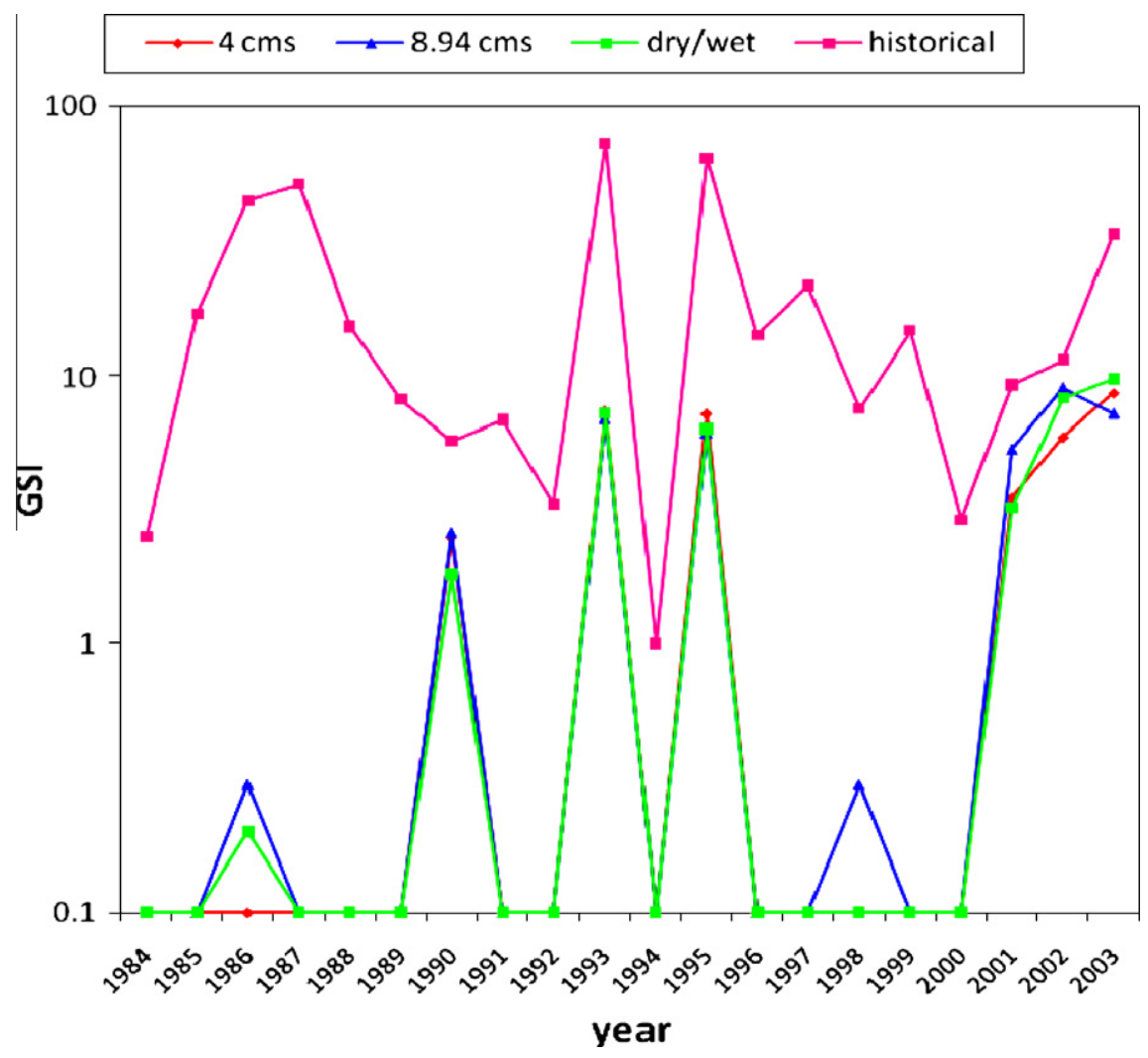

Fig. 4. The GSI values obtained from CGA search results and historical operations during 1984-2003.

into the objective function to efficiently search for the optimal solutions and the Shih-Men Reservoir has great potential to increase its water supply capability for both human demand and ecological base flow requirements if advanced mathematic programming techniques, such as CGA, could be used and proper operational strategy is implemented.

\section{Acknowledgment}

This study is sponsored by the Water Resources Planning Institute, Water Resource Agency, Taiwan, Republic of China. The authors are indebted to the editors and reviewers for their valuable comments and suggestions. 
Table 5

Summarized table of the CGA results and historical operations.

\begin{tabular}{|c|c|c|c|c|c|c|c|c|c|}
\hline \multirow[t]{2}{*}{ Type (average) } & \multicolumn{3}{|c|}{ (1) GSI } & \multicolumn{3}{|c|}{ (2) Human shortage } & \multicolumn{3}{|c|}{ (3) Ecological shortage } \\
\hline & I & II & III & I & II & III & I & II & III \\
\hline \multicolumn{10}{|l|}{ CGA results } \\
\hline Drought & 3.60 & 3.69 & 3.90 & 31 & 34 & 32 & 3.0 & 54 & 50 \\
\hline Normal & 0.05 & 0.07 & 0.04 & 3 & 3 & 2 & 0.0 & 10 & 1 \\
\hline Wet & 0.76 & 0.99 & 0.63 & 9 & 11 & 8 & 0.3 & 15 & 6 \\
\hline 20 years & 1.80 & 1.90 & 1.80 & 16 & 18 & 16 & 1.0 & 29 & 23 \\
\hline \multicolumn{10}{|c|}{ Historical operations } \\
\hline Drought & 29.2 & & & 60 & & & 4.0 & 57 & 55 \\
\hline Normal & 26.4 & & & 48 & & & 0.0 & 16 & 14 \\
\hline Wet & 8.5 & & & 34 & & & 0.1 & 18 & 13 \\
\hline 20 years & 20.3 & & & 47 & & & 2.0 & 33 & 30 \\
\hline
\end{tabular}

(1) GSI.

(2) Human shortage: water shortage (MCM) of human demand.

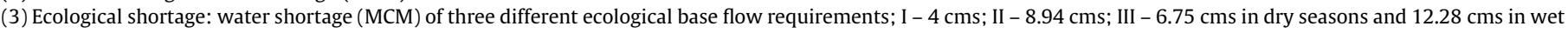
seasons.

\section{References}

Abedian, A., Ghiasi, M.H., Dehghan-Manshadi, B., 2006. Effect of a linearexponential penalty function on the GA's efficiency in optimization of a laminated composite panel. International Journal of Computational Intelligence 2 (1), 5-11.

Arthington, A.H., Bunn, S.E., Poff, N.L.R., Naiman, R.J., 2006. The challenge of providing environmental flow rules to sustain river ecosystems. Ecological Applications 16 (4), 1311-1318.

Bauer, M., Olsson, O., 2008. Integration of enhanced reservoir operation (enrop) into IWRM in association with environmental and ecological aspects. In: XIIIth World Water Congress, Montpellier.

Cai, X., McKinney, D.C., Lasdon, L.S., 2001. Solving nonlinear water management models using a combined genetic algorithm and linear programming approach. Advances in Water Resources 24 (6), 667-676.

Chang, F.J., 2004. Integration of Ecohydrology in managing Water Resources. Water Resources Agency, Taipei, Taiwan (1/2) (in Chinese).

Chang, L.C., 2008. Guiding rational reservoir flood operation using penalty-type genetic algorithm. Journal of Hydrology 354, 65-74.

Chang, L.C., Chang, F.J., 2001. Intelligent control for modelling of real-time reservoir operation. Hydrological Processes 15 (9), 1621-1634.

Chang, F.J., Chen, L., Chang, L.C., 2005. Optimizing the reservoir operation rule curves by genetic algorithms. Hydrological Processes 19 (11), 2277-2289.

Chang, F.J., Tsai, M.J., Tsai, W.P., Herricks, E.E., 2008. Assessing the ecological hydrology of natural flow conditions in Taiwan. Journal of Hydrology 354, 7589.

Chang, F.J., Wu, T.C., Tsai, W.P., Herricks, E.E., 2009. Defining the ecological hydrology of Taiwan Rivers using multivariate statistical methods. Journal of Hydrology (on line).

Chaves, P., Chang, F.J., 2008. Intelligent reservoir operation system based on evolving artificial neural networks. Advances in Water Resources 31, 926-936.

Chen, L., Chang, FJ., 2007. Applying a real-coded multi-population genetic algorithm to multi-reservoir operation. Hydrological Processes 21 (5), 688-698.

Chen, Y.H., Chang, F.J., 2009. Evolutionary artificial neural networks for hydrological systems forecasting. Journal of Hydrology 367, 125-137.

Chen, L., McPhee, J., Yeh, W.W.G., 2007. A diversified multiobjective GA for optimizing reservoir rule curves. Advances in Water Resources 30 (5), 1082 1093.

Deep, K., Dipti., 2008. A self-organizing migrating genetic algorithm for constrained optimization. Applied Mathematics and Computation 198 (1), 237-250.

Galizia Tundisi, J., Matsumura-Tundisi, T., 2003. Integration of research and management in optimizing multiple uses of reservoirs: the experience in South America and Brazilian case studies. Hydrobiologia 500 (1), 231-242.

Gibbins, C.N., Soulsby, C., Jeffries, M.J., Acornley, R., 2001. Developing ecologically acceptable river flow regimes: a case study of Kielder reservoir and the Kielder water transfer system. Fisheries Management \& Ecology 8 (6), 463-485.
Harman, C., Stewardson, M., 2005. Optimizing dam release rules to meet environmental flow targets. River Research and Applications 21 (2-3), 113-129.

Holland, J.H., 1975. Adaptation in Natural and Artificial Systems. The University of Michigan Press, Ann Arbor, MI.

Hsu, S.K., 1995. Shortage indices for water-resources planning in Taiwan. Journal of Water Resources Planning and Management 121, 119-131.

Huang, W.C., Yuang, L.C., Lee, C.M., 2002. Linking genetic algorithm with stochastic dynamic programming to the long-term operation of multi-reservoir system. Water Resources Research 38 (12), 1304.

Katsifarakis, K.L., Petala, Z., 2006. Combining genetic algorithms and boundary elements to optimize coastal aquifers' management. Journal of Hydrology 327 (1-2), 200-207.

Kerachian, R., Karamouz, M., 2007. A stochastic conflict resolution model for wate quality management in reservoir-river systems. Advances in Water Resources $30(4), 866-882$.

Lytle, D.H., Poff, N.L., 2004. Adaptation to natural flow regimes. Trends in Ecology and Evolution 19 (2), 94-100.

McCartney, M.P., Awulachew, S.B., Seleshi, Y., Prasad, K., King, J., Tarekegn, D., 2005. Decision support systems for dam planning and operation in Africa International Water Management Institute, Colombo, Sri Lanka (IWMI Working Paper 119).

Michalewicz, Z., Schoenauer, M., 1996. Evolutionary algorithms for constrained parameter optimization problems. Evolutionary Computation 4, 1-32.

Poff, N.L., Allan, J.D., Bain, M.B., Karr, J.R., Prestegaard, K.L., Richter, B.D., Sparks, R.E. Stromberg, J.C., 1997. The natural flow regime: a paradigm for river conservation and restoration. Bioscience 47 (11), 769-784.

Poff, N.L.R., Allan, J.D., Palmer, M.A., Hart, D.D., Richter, B.D., Arthington, A.H., Rogers, K.H., Meyer, J.L., Stanford, J.A., 2003. River flows and water wars: emerging science for environmental decision making. Frontiers in Ecology and the Environment 1 (6), 298-306.

Pusey, B.J., 1998. Methods addressing the flow requirements of fish. Comparative Evaluation of Environmental Flow Assessment Techniques: Review of Methods, pp. 66-105.

Richardson, J. T., Palmer, M.R., Liepins, G.E., Hilliard, M., 1989. Some guidelines for genetic algorithms with penalty functions. In: Proceedings of the Third International Conference on Genetic Algorithms Table of Contents, pp. 191-197.

Richter, B.D., Baumgartner, J.V., Powell, J., Braun, D.P., 1996. A method for assessing hydrologic alteration within ecosystems. Conservation Biology 10 (4), 11631174.

Stalnaker, C.B., Arnette, J.L., 1976. Methodologies for the Determination of Stream Resource Flow Requirements: An Assessment.

Suen, J., Eheart, J.W., 2006. Reservoir management to balance ecosystem and human needs: incorporating the paradigm of the ecological flow regime. Water Resources Research 42, W03417.

Tennant, D.L., 1976. Instream flow regimens for fish, wildlife, recreation and related environmental resources. Fisheries 1 (4), 6-10. 